\title{
Two new species and one new record of Kretzschmaria (Ascomycota, Xylariales) from Iran
}

\section{Pourmoghaddam $\mathrm{MJ}^{1,2}$, Khodaparast $\mathrm{SA}^{1^{*}}$, Krisai-Greilhuber $\mathrm{I}^{2}$, Voglmayr $\mathbf{H}^{2}$ and Stadler $\mathbf{M}^{3}$}

\author{
${ }^{1}$ Department of Plant Protection, Faculty of Agricultural Sciences, University of Guilan, Rasht, Iran \\ ${ }^{2}$ Division of Systematic and Evolutionary Botany, Department of Botany and Biodiversity Research, University of \\ Vienna, Rennweg 14, 1030 Wien, Austria \\ ${ }^{3}$ Helmholtz-Zentrum für Infektionsforschung GmbH, Dept. Microbial Drugs, Inhoffenstrasse 7, 38124, Braunschweig, \\ Germany
}

Pourmoghaddam MJ, Khodaparast SA, Krisai-Greilhuber I, Voglmayr H, Stadler M 2018 - Two new species and one new record of Kretzschmaria (Ascomycota, Xylariales) from Iran. Mycosphere 9(6), 1197-1208, Doi 10.5943/mycosphere/9/6/9

\begin{abstract}
Kretzschmaria hedjaroudei and Kretzschmaria iranica are described as new species based on collections from dead wood in northern Iran and on evidence from morphology and molecular phylogenetic data. Kretzschmaria hedjaroudei is phylogenetically close to Kretzschmaria deusta, from which it differs in its stromatal morphology, ascospore size and the size of the apical apparatus. Kretzschmaria iranica is similar to Kretzschmaria pavimentosa, but distinguishable by smaller ascospore size. Phylogenetic analyses of a combined matrix of the internal transcribed spacer (ITS) region of the nuclear rDNA and of $\alpha$-actin (ACT1) gene sequences strongly support their status as two distinct new species within the genus Kretzschmaria. Moreover, Kretzschmaria zonata, a species previously only known from tropical countries, is encountered for the first time in Iran.
\end{abstract}

Key words -2 new species - Biodiversity - Biosystematics - Phylogeny - Xylariaceae

\section{Introduction}

The Xylariaceae have traditionally comprised the stromatic genera of the Xylariales, but recently, the family was re-organised and now comprises mainly genera with a geniculosporiumlike anamorph (Daranagama et al. 2018) and this was followed in the latest classification of Wijayawardene et al. (2018). Wendt et al. (2018) resurrected and emended the Hypoxylaceae for Hypoxylon and most other genera featuring a nodulisporium-like anamorph and transferred Biscogniauxia, Camillea and related genera to the Graphostromataceae. The Xylariaceae sensu stricto is, with regard to the number of genera and species, still the largest family in the Xylariales and even contains several genera that form very small stromata or are only recognised to belong to it from studies of the anamorphs and molecular phylogenies (Daranagama et al. 2018). As recently summarised by Helaly et al. (2018), these fungi have a very interesting lifestyle, as they are able to live as saprotrophs on wood or dung, but also constitute one of the predominant taxonomic groups among the endophytes of seed plants, while only a few species have been recognised as plant pathogens or associates of insects.

The genus Kretzschmaria Fries was described in 1849 with $K$. clavus as the type species. 
Martin (1970) emphasized the close relationship between Xylaria and Kretzschmaria, segregating them by the vertical orientation of perithecia and umbonate or aristate apices on the fertile parts. The last monographic treatment of the genus, in which the taxonomy of Kretzschmaria has been linked to the holomorphic concept of the Xylariaceae, goes back to Rogers \& Ju (1998). Strikingly, the genus has received little attention since then, and many species are still only known from their teleomorphs and have never been cultured and studied by molecular phylogenetic methods.

Stromata of Kretzschmaria species are superficial, peltate, discoid, restricted pulvinate, to effused pulvinate, usually gregarious, discrete, or fused into crusts, stipitate or sessile. Mature stromata lack $\mathrm{KOH}$ extractable pigments and have a carbonaceous outer layer encrusting a rather soft white to blackish inner layer. The asci are cylindrical, stipitate, evanescent or persistent, with an urn-shaped, amyloid apical apparatus. Ascospores are medium, dark, or blackish brown, ellipsoid to fusoid with a straight or sigmoid germ slit ranging over the entire spore length to much less than spore-length on the less convex side and have a perispore indehiscent in $10 \% \mathrm{KOH}$ (Rogers \& Ju 1998, Mugambi et al. 2009).

The genus is informally divided into kretzschmarioid and ustulinoid taxa. Kretzschmarioid taxa are characterised by stipitate or sessile stromata, with the fertile parts and/or stipes often fused, usually with entire margins. Individual fertile parts rarely exceed $1 \mathrm{~cm}$ diam. and the anamorphs may be coremioid or noncoremioid. Ustulinoid taxa have more or less sessile stromata, to which frequently rhizoid-like processes or narrow connectives are attached. Their stromata usually have crenate margins, with fertile parts usually exceeding $1 \mathrm{~cm}$ diam., and the anamorphs (where known) are noncoremioid.

Species of this genus are identified from all over the world, and they are widespread in temperate and tropical areas (Rogers \& Ju 1998). Currently, about 23 species are accepted (Rogers \& Ju 1998, Hladki \& Romero 2001, Rogers \& Ju 2004, Mugambi et al. 2009, Pereira et al. 2009, Yun et al. 2016), most of which are causing white rot and root rot (Rogers \& Ju 1998). Analysis of $\beta$-tubulin, $\alpha$-actin and RPB2 sequence data confirmed that Kretzschmaria is phylogenetically closely related to Xylaria (Hsieh et al. 2010). In Iran, K. deusta is the only species of the genus reported so far (Saber 2002).

During a survey of Xylariaceae in Guilan and Mazandaran provinces in Iran, two Kretzschmaria taxa were found that could not be identified to species. The combination of morphological and molecular data did not result in any matches with known taxa, hence they are described here as new species. Furthermore, an additional Kretzschmaria species was recorded as new for Iran.

\section{Materials \& Methods}

\section{Morphological characterisation}

Samples were collected from Guilan and Mazandaran provinces (N Iran) during 2016. Parts of corticated branches and trunks of infested trees containing xylariaceous stromata were transferred to the laboratory. Single ascospores cultures were obtained from ascomata based on the method described by Rogers \& Ju 1998. The fungus was described from cultures grown at $20{ }^{\circ} \mathrm{C}$ on $2 \%$ Difco oatmeal agar (OA). Microscopy of ascospores and asci was done in distilled water, and Melzer's reagent was used for staining of the apical ascus apparatus. At least 30, 10 and 5 measurements were determined for ascospores, asci and ascus apical apparatus, respectively. Macrophotographs were obtained with a Keyence VHX-6000 microscope. Light microscopy with Nomarski differential interference contrast (DIC) was done using a Zeiss Axio Imager.A1 compound microscope equipped with a Zeiss Axiocam 506 colour digital camera. Usually, more than one photo was taken and selected photos of each structure were mounted in a single photo plate using Photoshop (version CS5). Living cultures have been deposited in the Fungal Herbarium of the Iranian Research Institute of Plant Protection (IRAN) and STMA (HZI culture collection, Helmholtz Centre for Infection Research, Braunschweig, Germany). Also, dried vouchers have 
been deposited in the fungarium of the Department of Plant Protection, Faculty of Agricultural Science, University of Guilan, Guilan, Iran (GUM).

\section{DNA extraction, PCR amplification and sequencing}

Genomic DNA was extracted directly from perithecia or mycelia produced in culture using Chelex 5\% (Walsh et al. 1991, Hirata \& Takamatsu 1996). DNA preparations were stored at $-20{ }^{\circ} \mathrm{C}$ until used for PCR. The DNA amplification was obtained by polymerase chain reaction (PCR). A region spanning ITS1, 5.8S and ITS2 of rDNA was amplified as described by Khodaparast et al. (2012) using the primers ITS5 and ITS4 (White et al. 1990). Part of the $\alpha$-actin gene (ACT1) region was amplified with primers ACT-512F and ACT-783R (Carbone \& Kohn 1999). DNA was cyclesequenced using the ABI PRISM Big Dye Terminator Cycle Sequencing Ready Reaction Kit v. 3.1 (Applied Biosystems, Warrington, UK) and the PCR primers. Sequencing was performed on an automated DNA sequencer (ABI 3730xl Genetic Analyzer, Applied Biosystems). Sequences derived from this study were deposited at the NCBI GenBank nucleotide database (http://www.ncbi.nlm.nih.gov); for GenBank accession numbers see Table 1.

\section{Sequence alignment and phylogenetic analyses}

The raw trace files were inspected and edited with MEGA v. 7 software (Kumar et al. 2016). The sequences were compared with sequences from GenBank using BLAST searches; sequences with high similarity were added to the matrices. Sequences of an accession of Hypoxylon fragiforme (JN979419, AY951831) and of $H$. howeanum (JQ009323, AY951839) from Hypoxylaceae were included as outgroups to root the trees. The details on the sequences included in the phylogenetic analyses are given in Table 1. A basic alignment of the obtained sequences in this study together with the sequence data from GenBank and the outgroup sequences was first done using MAFFT v. 7 (http://mafft.cbrc.jp/alignment/server/index.html) (Katoh et al. 2002); and when considered necessary, manual adjustments were made in MEGA v. 7 (Kumar et al. 2016). Maximum likelihood (ML) analyses were performed with RAxML (Stamatakis 2006) as implemented in raxmlGUI 1.5 (Silvestro \& Michalak 2012), using the ML + rapid bootstrap setting and the GTRGAMMA substitution model with 1000 bootstrap replicates. The matrix was partitioned for the different gene regions. Bootstrap support (BS) below $70 \%$ was considered low, between 70-85\% medium and above $85 \%$ high. The matrix and the resulting tree have been $\begin{array}{lllll}\text { deposited at } & \text { Treebase under submission }\end{array}$ (http://purl.org/phylo/treebase/phylows/study/TB2:S23376?X-accesscode $=$ f5b91e2c76a8997905731af44909f2d5\&format=html)

\section{Results}

\section{Sequencing and molecular phylogeny}

The final alignment comprised sequences of 27 accessions of Kretzschmaria spp. and Xylaria spp. from GenBank and from the Iranian specimens and two Hypoxylon species as outgroups. Amplification of the ITS and ACT1 loci yielded fragments of approximately 700 and $300 \mathrm{bp}$, respectively. The final matrix contained $741 \mathrm{bp}$ from ITS and $234 \mathrm{bp}$ from ACT1. Of the 975 characters included in the combined analyses, 368 were parsimony informative (110 from ACT1, 258 from ITS). The best ML tree $(-\operatorname{lnL}=7791.715)$, revealed by RAxML, is shown as a phylogram in Fig. 1. In the phylogenetic analyses, the genus Xylaria was revealed as paraphyletic; however, without significant support of the tree backbone. The genus Kretzschmaria formed a monophylum but without significant support as well. Within Kretzschmaria, K. guyanensis and K. megalospora formed a highly supported (97\% BS) subclade in an unsupported sister group relationship to a highly supported (89\% BS) core Kretzschmaria subclade. The latter contained all taxa of our study from Iran. Moreover, five new sequences generated from Iranian material were clearly distinct from already published sequences belonging to the genus Kretzschmaria, of which four were 
morphologically revealed to belong to two undescribed species, while two others matched with $K$. zonata and $K$. deusta, respectively (Fig. 1).

Table 1 List of used strains for molecular phylogeny. Sequences in bold were generated during the present study

\begin{tabular}{|c|c|c|c|c|c|}
\hline Species & $\begin{array}{l}\text { GenBank Acc } \\
\text { No ITS }\end{array}$ & $\begin{array}{l}\text { GenBank Acc } \\
\text { No ACT }\end{array}$ & $\begin{array}{l}\text { Specimen or } \\
\text { strain ID }\end{array}$ & Origin & Reference \\
\hline $\begin{array}{l}\text { Kretzschmaria } \\
\text { clavus }\end{array}$ & EF026126 & EF025596 & $\begin{array}{l}\text { YMJ 114, } \\
\text { CBS } 122872\end{array}$ & French Guiana & Hsieh et al. (2010) \\
\hline K. deusta & KT281901 & KU684090 & $\begin{array}{l}\text { CBS 826.72, } \\
\text { CBS 163.93 }\end{array}$ & USA, Thailand & $\begin{array}{l}\text { U'Ren et al. (2016), } \\
\text { Senanayake et al. } \\
\text { (2015) }\end{array}$ \\
\hline K. deusta & MH084755 & MH056202 & $\begin{array}{l}\text { IRAN 3060c, } \\
\text { GUM1547 }\end{array}$ & Iran & This study \\
\hline K. guyanensis & GQ408901 & GU300079 & $\begin{array}{l}89062903 \\
\text { (HAST) }\end{array}$ & Taiwan & Hsieh et al. (2010) \\
\hline $\begin{array}{l}\text { K. hedjaroudei } \\
\text { sp. nov. }\end{array}$ & MH084757 & MH056204 & $\begin{array}{l}\text { IRAN 3061c, } \\
\text { STMA } 18005 \text {, } \\
\text { GUM1549 }\end{array}$ & Iran & This study \\
\hline $\begin{array}{l}\text { K. iranica sp. } \\
\text { nov. }\end{array}$ & MH084758 & MH056205 & GUM1550 & Iran & This study \\
\hline $\begin{array}{l}\text { K. iranica sp. } \\
\text { nov. }\end{array}$ & MH084759 & MH056206 & GUM1551 & Iran & This study \\
\hline $\begin{array}{l}\text { K. iranica sp. } \\
\text { nov. }\end{array}$ & MH084760 & MH056207 & GUM1552 & Iran & This study \\
\hline K. lucidula & EF026125 & EF025595 & YMJ 112 & French Guiana & Hsieh et al. (2010) \\
\hline K. megalospora & EF026124 & EF025594 & YMJ 229 & Malaysia & Hsieh et al. (2010) \\
\hline K.neocaledonica & GU300078 & GQ398236 & $\begin{array}{l}94031003 \\
\text { (HAST) }\end{array}$ & Taiwan & Hsieh et al. (2010) \\
\hline K. pavimentosa & GU300077 & GQ398235 & 109 (JDR) & Taiwan & Hsieh et al. (2010) \\
\hline K. sandvicensis & GU300078 & GQ398234 & 113 (JDR) & $\begin{array}{l}\text { USA, Hawaiian } \\
\text { Islands }\end{array}$ & Hsieh et al. (2010) \\
\hline K. zonata & MH084756 & MH056203 & GUM1548 & Iran & This study \\
\hline $\begin{array}{l}\text { Xylaria } \\
\text { arbuscula }\end{array}$ & KY610394 & GQ421286 & $\begin{array}{l}89041211 \\
\text { (HAST), } \\
\text { CBS126415 }\end{array}$ & $\begin{array}{l}\text { Germany, } \\
\text { Taiwan }\end{array}$ & $\begin{array}{l}\text { Hsieh et al. (2010), } \\
\text { Wendt et al. (2018) }\end{array}$ \\
\hline X. areolata & GU300080 & GQ408902 & $\begin{array}{l}89041211 \\
\text { (HAST), } 543 \\
\text { (HAST, JF) }\end{array}$ & $\begin{array}{l}\text { French West } \\
\text { Indies }\end{array}$ & Hsieh et al. (2010) \\
\hline X. bambusicola & EF026123 & AY951873 & YMJ 205 & Taiwan & Hsieh et al. (2010) \\
\hline X. coccophora & GU300093 & GQ421289 & $\begin{array}{l}786 \text { (HAST, } \\
\text { JF) }\end{array}$ & French Guiana & Hsieh et al. (2010) \\
\hline X. cranioides & GU300075 & GQ398233 & 226 (HAST) & Taiwan & Hsieh et al. (2010) \\
\hline X. fissilis & GU300073 & GQ398231 & $\begin{array}{l}367 \text { (HAST, } \\
\text { JF) }\end{array}$ & $\begin{array}{l}\text { French West } \\
\text { Indies }\end{array}$ & Hsieh et al. (2010) \\
\hline X. hypoxylon & KY204024 & GQ427195 & $\begin{array}{l}95082001 \\
\text { (HAST), CBS } \\
122620\end{array}$ & $\begin{array}{l}\text { Taiwan, } \\
\text { Sweden }\end{array}$ & $\begin{array}{l}\text { Hsieh et al. (2010), } \\
\text { Sir et al. (2016) }\end{array}$ \\
\hline X. multiplex & GU300098 & GQ427198 & $\begin{array}{l}580 \text { (HAST, } \\
\text { JF) }\end{array}$ & $\begin{array}{l}\text { French West } \\
\text { Indies }\end{array}$ & Hsieh et al. (2010) \\
\hline X. muscula & GU300087 & GQ408909 & $\begin{array}{l}520 \text { (HAST, } \\
\text { JF) }\end{array}$ & $\begin{array}{l}\text { French West } \\
\text { Indies }\end{array}$ & Hsieh et al. (2010) \\
\hline X. oligotoma & GU300092 & GQ421288 & $\begin{array}{l}784 \text { (HAST, } \\
\text { JF) }\end{array}$ & French Guiana & Hsieh et al. (2010) \\
\hline X. polymorpha & GU322460 & GQ452364 & 1012 (JDR) & USA & Hsieh et al. (2010) \\
\hline
\end{tabular}


Table 1 Continued.

\begin{tabular}{|l|l|l|l|l|l|}
\hline Species & $\begin{array}{l}\text { GenBank Acc } \\
\text { No ITS }\end{array}$ & $\begin{array}{l}\text { GenBank Acc } \\
\text { No ACT }\end{array}$ & $\begin{array}{l}\text { Specimen or } \\
\text { strain ID }\end{array}$ & Origin & Reference \\
\hline X. tuberoides & GU300074 & GQ398232 & $\begin{array}{l}475 \text { (HAST, } \\
\text { JF) }\end{array}$ & $\begin{array}{l}\text { French West } \\
\text { Indies }\end{array}$ & Hsieh et al. (2010) \\
\hline X. venustula & GU300091 & GQ421287 & $\begin{array}{l}88113002 \\
\text { (HAST) }\end{array}$ & Taiwan & Hsieh et al. (2010) \\
\hline $\begin{array}{l}\text { Hypoxylon } \\
\text { fragiforme }\end{array}$ & AY951831 & JN979419 & YMJ 387 & France & Hsieh et al. (2005) \\
\hline H. howeanum & JQ009323 & AY951839 & YMJ 388 & France & Hsieh et al. (2005) \\
\hline
\end{tabular}

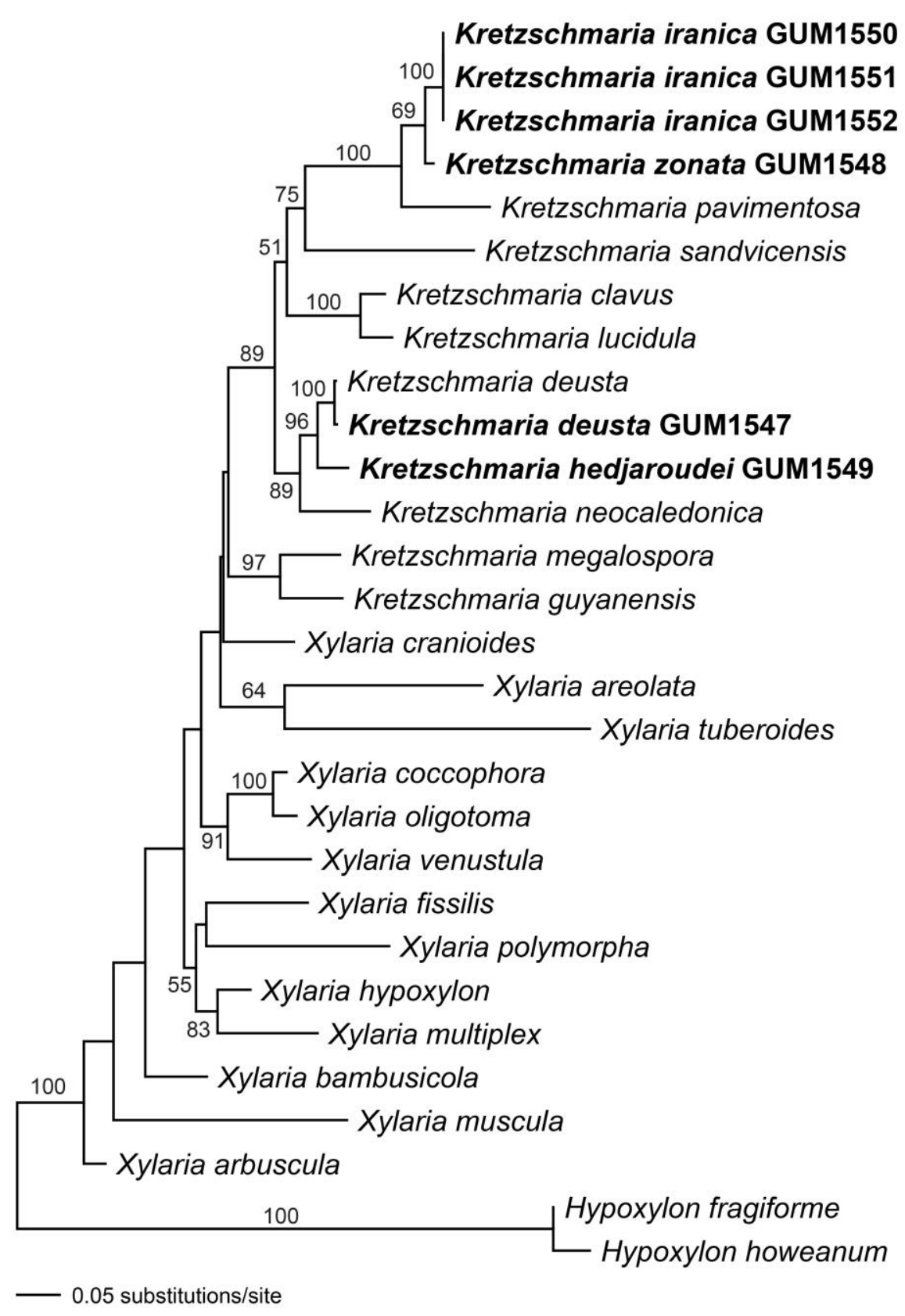

Figure 1 - Phylogram of the best ML tree $(-\operatorname{lnL}=7791.715)$ revealed by RAxML from an analysis of the combined ITS-ACT1 matrix of Kretzschmaria and Xylaria species, showing the phylogenetic position of the Iranian Kretzschmaria isolates (in bold, with herbarium numbers following the taxon names). ML bootstrap support above $50 \%$ is given above or below the branches. The tree was rooted to with two Hypoxylon species. 


\section{Taxonomic part}

The combination of morphological and molecular data led to the conclusion that Kretzschmaria hedjaroudei and $K$. iranica represent undescribed species of the Xylariaceae, and are therefore described as new. In addition, K. zonata is a new record for Iran.

Kretzschmaria hedjaroudei Pourmoghaddam \& Khodap, sp. nov.

Fig. 2

MycoBank: MB 827993; Facesoffungi number: FoF 04958

Holotype - Iran, Mazandaran Province, Tonekabon County, Dohezar forest, on wood or bark of a dead branch, N 3647'21.02", E 50 52'34.07", 1 m elev.,28 Oct 2016; M.J. Pourmoghaddam (GUM1549, consisting of a dried specimen. Ex-type cultures IRAN 3061C \& STMA 18005. GenBank Acc. No: ITS - MH084757, ACT1- MH056204).

Etymology - In honor of the Iranian mycologist Ghorban Ali Hedjaroude, a pioneer in the exploration of Iranian fungi.

Teleomorph - Stromata superficial, pulvinate, discrete, sessile, up to $2 \mathrm{~cm}$ long $\times 1-1.4 \mathrm{~cm}$ wide $\times 2.28-2.54 \mathrm{~mm}$ thick, attachment to substrate with strong connective, steep margins; surface black to dark brown, with inconspicuous perithecial mounds and cracks, carbonaceous immediately beneath surface; tissue between and beneath perithecia black to dark brown. Perithecia obovoid to cylindrical, $0.75-1.15 \mathrm{~mm}$ wide $\times 1.15-1.8 \mathrm{~mm}$ high, ostioles coarsely papillate. Asci with amyloid, urn-shaped apical apparatus, $6-8 \mu \mathrm{m}$ high $\times 3-5 \mu \mathrm{m}$ wide, stipe up to $200 \mu \mathrm{m}$ long, sporebearing part 90-140 × 12-14 $\mu \mathrm{m}$. Ascospores smooth, unicellular, brown to dark brown, fusoid to ellipsoid, inequilateral, with narrowly or broadly rounded ends, 24-30 $\times 5-7 \mu \mathrm{m}$, with straight germ slit much less than spore-length on flattened side; perispore indehiscent in $10 \% \mathrm{KOH}$.

Cultures and anamorph - Cultures on $2 \%$ OA reaching $90 \mathrm{~mm}$ diam. in 4 weeks, first whitish, felty and zonate, then becoming gray from center outwards with concentric zones. Asexual morph not produced in culture.

Host - on wood or bark of a dead branch

Known distribution - Iran

Notes - Kretzschmaria hedjaroudei is closely related to K. deusta; however, it can be easily distinguished by its stromatal shape, smaller diameter and steep margins of stromata, coarsely papillate ostioles, smaller ascospores $(24-30 \times 5-7$ vs. 27-35 $\times 7-9 \mu \mathrm{m})$ and larger apical apparatus $(6-8 \times 3-5$ vs. $4-6 \times 3-4 \mu \mathrm{m})$ (Rogers $\& \mathrm{Ju} 1998)$. It is also similar to $K$. parvistroma according to the shape of stromata, which according to Mugambi et al. (2009) differs by much larger ascospores (34-)37-38(-39) $\times(10-) 12-13 \mu \mathrm{m}$.

Kretzschmaria iranica Pourmoghaddam \& Khodap, sp. nov.

Fig. 3

MycoBank:MB 827994; Facesoffungi number: FoF 04959

Holotype - Iran, Guilan Province, Fouman County, Ghalerodkhan forest, on fallen wood of

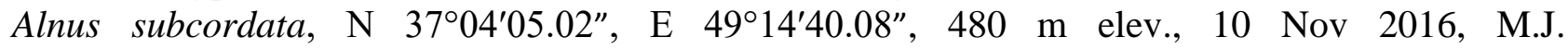
Pourmoghaddam GUM1551, consisting of a dried specimen. GenBank Acc. No: ITS -MH084759, ACT1 - MH056206).

Etymology - Named after the country from where it was collected, Iran

Teleomorph - Stromata superficial, pulvinate to effused-pulvinate, densely aggregated, up to $8.5 \mathrm{~cm}$ long $\times 2-4 \mathrm{~cm}$ wide $\times 1.8-3.45 \mathrm{~mm}$ thick, with broad attachment to substrate and narrow connective, margins steep; surface brown to dark brown, with inconspicuous perithecial mounds, often with reticulate cracks, carbonaceous immediately beneath surface; tissue between and beneath perithecia brown to dark brown. Perithecia obovoid to lanceolate, $0.6-0.9 \mathrm{~mm}$ wide $\times 0.75-1.15$ $\mathrm{mm}$ high, ostioles finely papillate. Asci with amyloid, urn-shaped apical apparatus, $7-10 \mu \mathrm{m}$ high $\times$ 4.5-7 $\mu \mathrm{m}$ wide, stipe up to $150 \mu \mathrm{m}$ long, spore-bearing part 80-130 $\times 10-15 \mu \mathrm{m}$. Ascospores smooth, unicellular, dark to blackish brown, fusoid to ellipsoid, inequilateral, with narrowly or broadly rounded ends, $29-40 \times 8-12(-13) \mu \mathrm{m}$, with straight germ-slit slightly less than sporelength on flattened side; perispore indehiscent in $10 \% \mathrm{KOH}$.

Host - on fallen wood of Alnus subcordata 


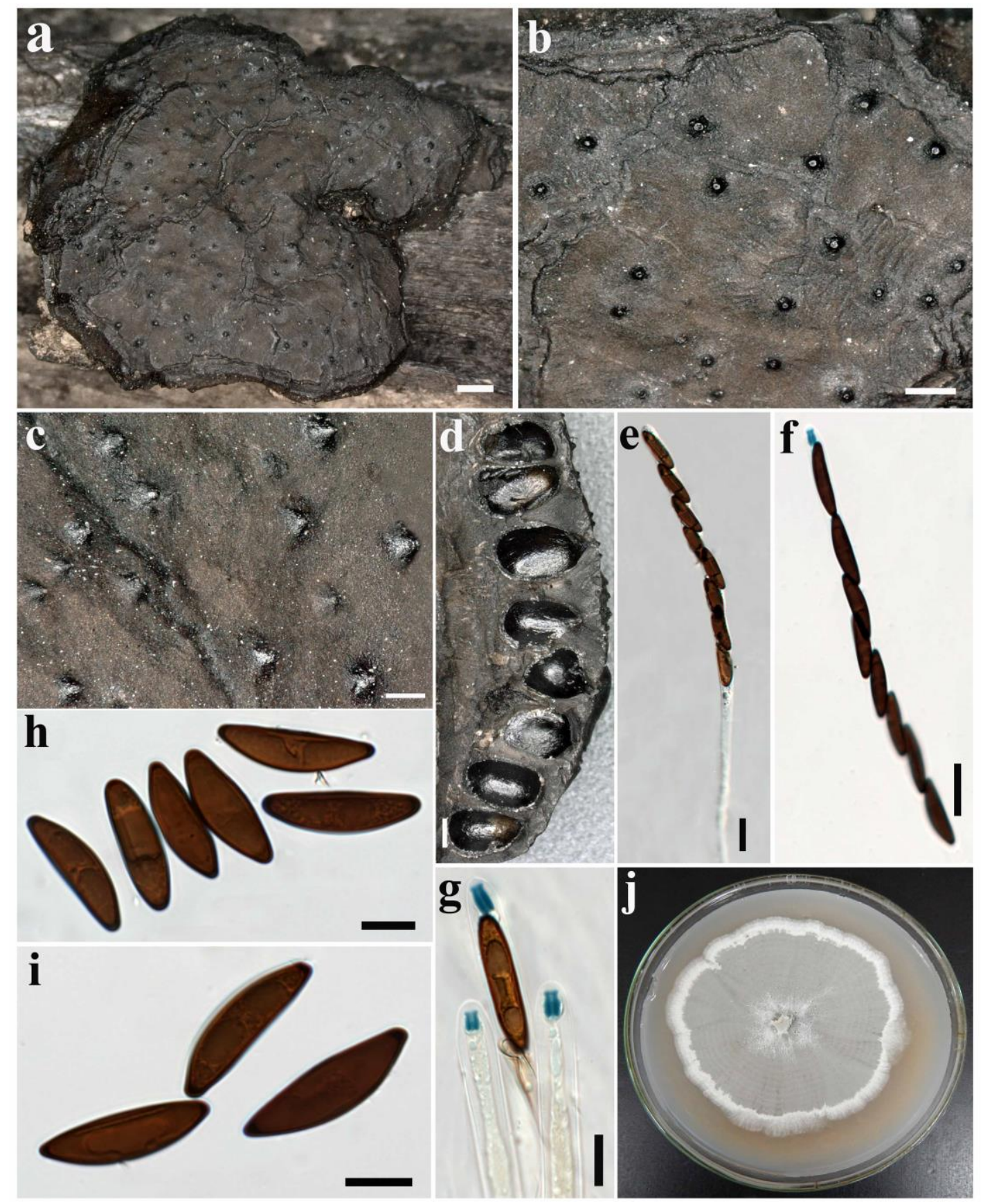

Figure 2 - Kretzschmaria hedjaroudei (Holotype). a Stromata habit. b Close-up view of stromata surface. c Close-up view of ostiolar discs. d Stroma in vertical section showing perithecia. e Asci. f Asci, showing apical apparatus in Melzer's reagent. g Apical apparatus in Melzer's reagent. $\mathrm{h}-\mathrm{i}$ Ascospores in water, showing germ slits. $\mathrm{j}$ Culture on OA. Scale bars: $\mathrm{a}=1 \mathrm{~mm}, \mathrm{~b}=0.4 \mathrm{~mm}$, $\mathrm{c}=0.2 \mathrm{~mm}, \mathrm{~d}=0.5 \mathrm{~mm}, \mathrm{e}-\mathrm{f}=20 \mu \mathrm{m}, \mathrm{g}-\mathrm{i}=10 \mu \mathrm{m}$.

Known distribution - Iran

Additional material examined - Iran, Guilan Province, Fouman County, Ghalerodkhan

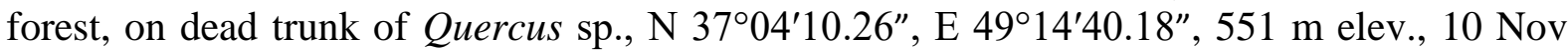
2016, leg. M.J. Pourmoghaddam (GUM1552, consisting of a dried specimen. GenBank Acc. No: ITS - MH084760, ACT1 - MH056207). Iran, Mazandaran Province, Tonekabon County, Dohezar forest, on dead trunk of Pterocarya fraxinifolia, N 36 47'21.02", E 50 52'34.07", $1 \mathrm{~m}$ elev., 28 Oct 2016, leg. M.J. Pourmoghaddam (GUM1550, consisting of a dried specimen. GenBank Acc. No: ITS - MH084758, ACT1 - MH056205). 
Notes - Kretzschmaria iranica has morphological similarities to $K$. pavimentosa, but differs by a larger apical apparatus $(7-10 \times 4.5-7$ vs. 6-9 $\times 4.5-6 \mu \mathrm{m})$, smaller ascospores $(29-40 \times 8-12$ $(-13)$ vs. $35-54(-56) \times 7.5-11 \mu \mathrm{m})$ and in the length of germ-slit, which is similar to $K$. deusta.

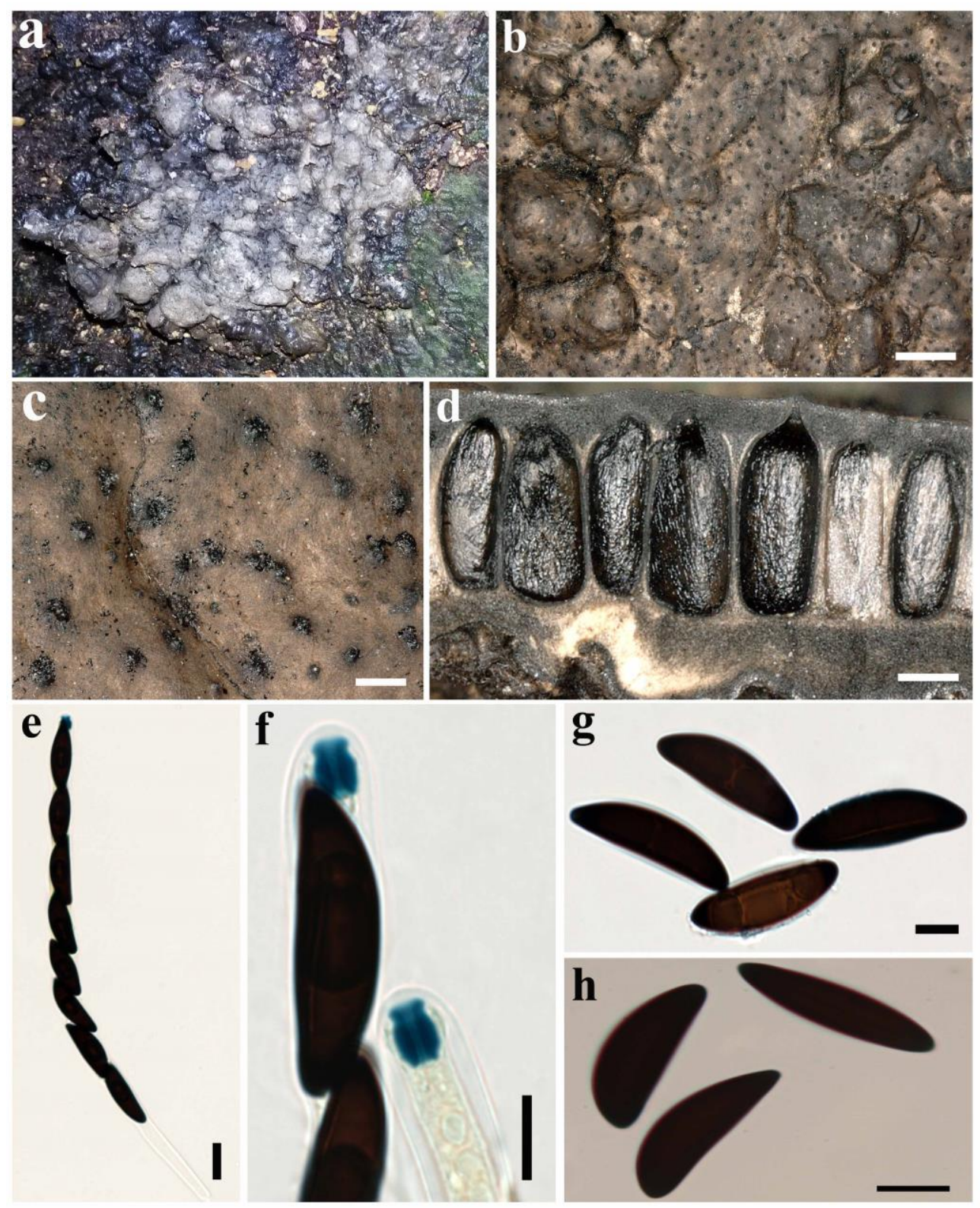

Figure 3 - Kretzschmaria iranica (Holotype). a Stromatal habit. b Close-up view of stromata surface. c Close-up view of ostiolar discs. d Stroma in vertical section showing perithecia. e Asci, showing apical apparatus in Melzer's reagent. f Apical apparatus in Melzer's reagent. $g$ Ascospores in water, showing germ slits. h Ascospores in $10 \% \mathrm{KOH}$, showing indehiscent perispore. Scale bars: $\mathrm{b}=2 \mathrm{~mm}, \mathrm{c}=0.3 \mathrm{~mm}, \mathrm{~d}=0.4 \mathrm{~mm}, \mathrm{e}=20 \mu \mathrm{m}, \mathrm{f}-\mathrm{h}=10 \mu \mathrm{m}$.

Kretzschmaria zonata (Lév.) P. Martin, J. S. African Bot. 42: 75 (1976).

Fig. 4

Teleomorph - Stromata superficial, pulvinate to effused-pulvinate, densely aggregated, up to $8.5 \mathrm{~cm}$ long $\times 2-3.5 \mathrm{~cm}$ wide $\times 1.8-2.54 \mathrm{~mm}$ thick, with broad attachment to substrate and narrow connective, sloped margins; surface brown to dark brown, with inconspicuous perithecial mounds, often with reticulate cracks, carbonaceous immediately beneath surface; tissue between and beneath perithecia brown to dark brown. Perithecia with very variable shapes, $0.6-0.75 \mathrm{~mm}$ diam $\times 0.5-0.9$ $\mathrm{mm}$ high, ostioles papillate. Asci with amyloid, urn-shaped apical apparatus, 7-9 $\mu \mathrm{m}$ high $\times 5-7$ $\mu \mathrm{m}$ wide, stipe up to $150 \mu \mathrm{m}$ long, spore-bearing part 80-130 $\times 11-13 \mu \mathrm{m}$. Ascospore smooth, 
unicellular, dark to blackish brown, fusoid to ellipsoid, inequilateral, 30-35(-40) $\times 8-11 \mu \mathrm{m}$, with straight germ-slit slightly shorter than spore-length on flattened side; perispore indehiscent in $10 \%$ $\mathrm{KOH}$.

Material examined - Iran, Guilan Province, Talesh, Gisom forest, on fallen wood of Parrotia

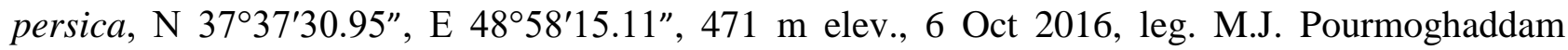
(GUM1548, consisting of a dried specimen. GenBank Acc. No: ITS - MH084756, ACT1 MH056203).

Notes - Kretzschmaria zonata is similar to $K$. deusta in having the same stromatal morphology and an indehiscent perispore in $10 \% \mathrm{KOH}$. However, it differs by darker and wider ascospores with a slightly longer germ slit (Rogers \& Ju 1998). The characters of the Iranian specimen are in accordance with K. zonata as defined by Rogers \& Ju (1998), except that the ascospores were slightly longer $(30-35(40-) \times 8-11$ vs. $21-34 \times 8.5-12 \mu \mathrm{m})$.
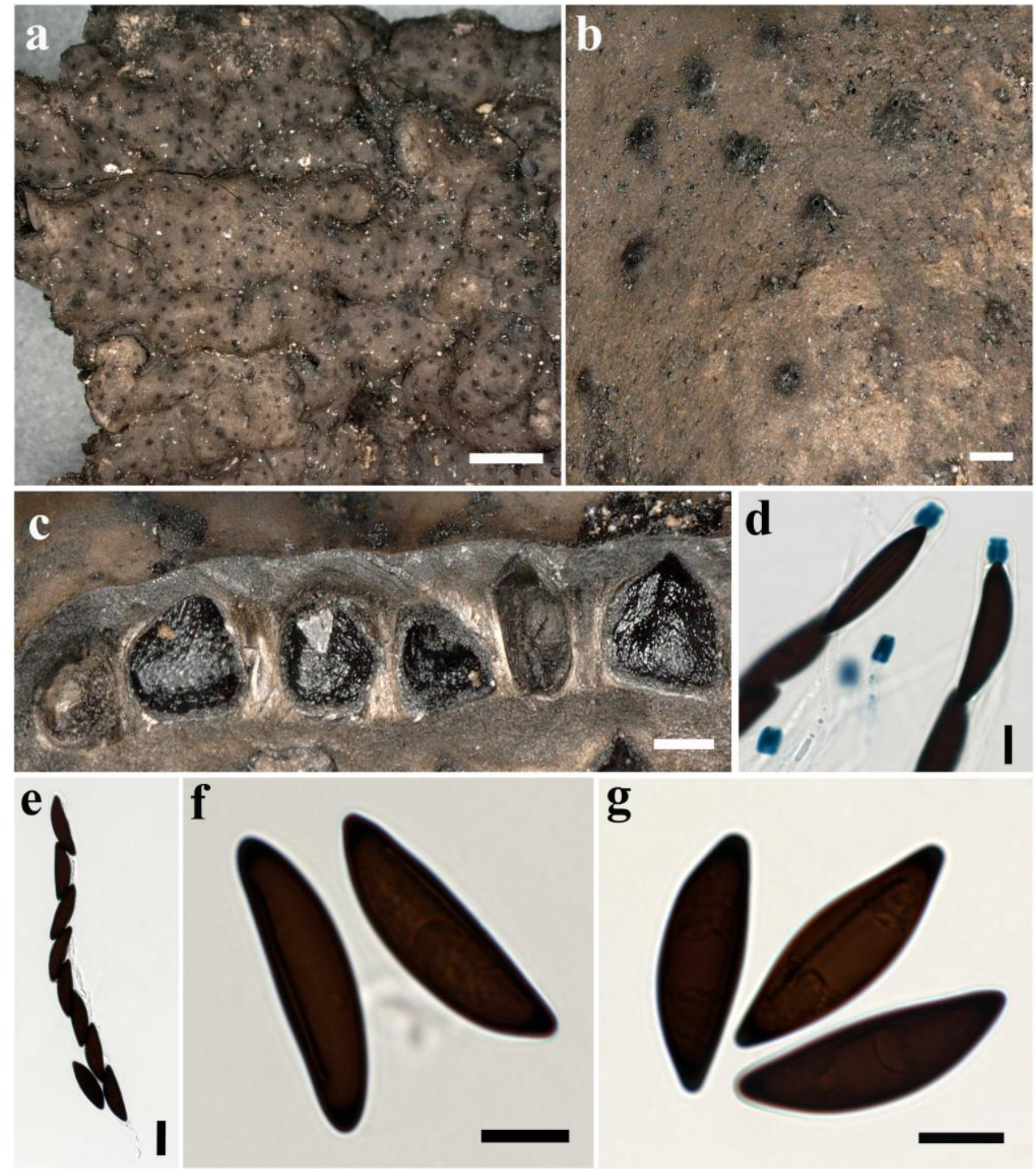

Figure 4 - Kretzschmaria zonata. a Close-up view of stromatal surface. b Close-up view of ostiolar discs. c Stroma in vertical section showing perithecia. d Apical apparatus in Melzer's reagent. e Asci. $\mathrm{f}-\mathrm{g}$ Ascospores in water, showing germ slits. Scale bars: $\mathrm{a}=2 \mathrm{~mm}, \mathrm{~b}=0.2 \mathrm{~mm}, \mathrm{c}=0.4$ $\mathrm{mm}, \mathrm{d}, \mathrm{f}, \mathrm{g}=10 \mu \mathrm{m}, \mathrm{e}=20 \mu \mathrm{m}$.

Kretzschmaria deusta (Hoffm.: Fr.) P. Martin, J. S. African Bot. 36: 80 (1970).

Teleomorph - Stromata superficial, pulvinate to effused-pulvinate, densely aggregated, up to 
$7.5 \mathrm{~cm}$ long $\times 2-5.2 \mathrm{~cm}$ wide $\times 2.8-4.5 \mathrm{~mm}$ thick, with broad attachment to substrate and narrow connective, sloped margins; surface black to blackish brown, with inconspicuous perithecial mounds, often with reticulate cracks, carbonaceous immediately beneath surface; tissue between and beneath perithecia brown to dark brown. Perithecia spherical to obovoid, $1-1.8 \mathrm{~mm}$ wide $\times 1-2$ $\mathrm{mm}$ high, ostioles papillate. Asci with amyloid, urn-shaped apical apparatus, 4-6 $\mu \mathrm{m}$ high $\times 2.5-4$ $\mu \mathrm{m}$ wide, stipe up to $250 \mu \mathrm{m}$ long, spore-bearing part 100-150 $\times 10-14 \mu \mathrm{m}$. Ascospores smooth, unicellular, brown to dark brown, fusoid-inequilateral, 25-34 ×5.5-8 (-9) $\mu \mathrm{m}$, with straight germslit much less than spore-length on flattened side; perispore indehiscent in $10 \% \mathrm{KOH}$.

Cultures and anamorph - Cultures on $2 \%$ OA reaching $90 \mathrm{~mm}$ diam. in 5 weeks, first whitish, felty and zonate, then becoming grey from centre outwards with concentric zones. Asexual morph not produced in culture.

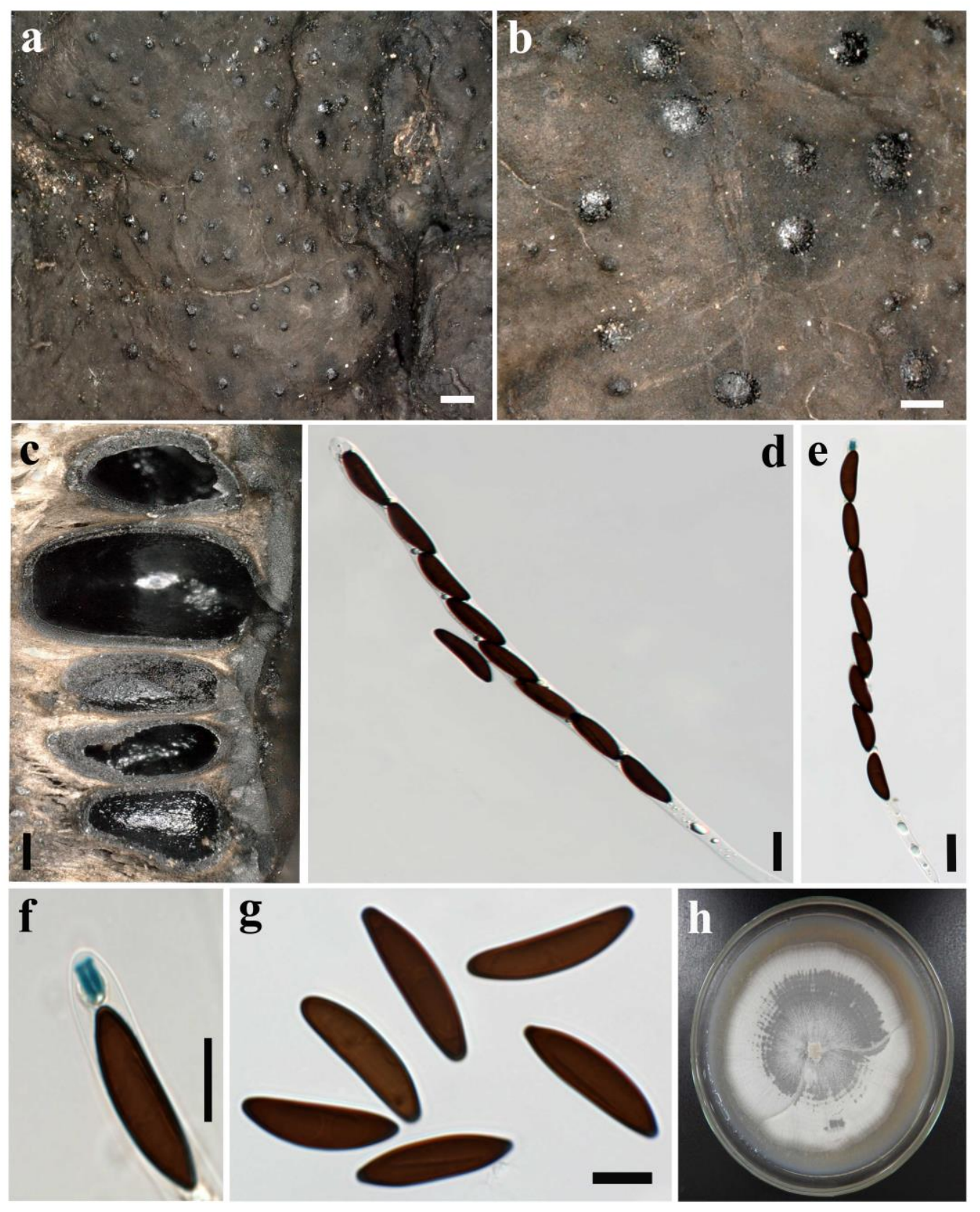

Figure 5 - Kretzschmaria deusta. a Close-up view of stromatal surface. b Close-up view of ostiolar discs. c Stroma in vertical section showing perithecia. d Asci. e Asci, showing apical apparatus in Melzer's reagent. f Apical apparatus in Melzer's reagent. g Ascospores in water, showing germ slits. h Culture on OA. Scale bars: $\mathrm{a}=1 \mathrm{~mm}, \mathrm{~b}=0.4 \mathrm{~mm}, \mathrm{c}=0.4 \mathrm{~mm}, \mathrm{~d}-\mathrm{e}=20 \mu \mathrm{m}, \mathrm{f}-\mathrm{g}=10 \mu \mathrm{m}$. 
Material examined - Iran, Guilan Province, Siahkal, Deilaman forest, on dead trunk of Fagus orientalis, N 3653'11.27”, E 4954'31.67”, 1432 m elev., 3 Oct 2016, M.J. Pourmoghaddam (GUM1547, consisting of a dried specimen. Ex-type cultures IRAN 6030C. GenBank Acc. No: ITS - MH084755, ACT1 - MH056202).

Notes - Kretzschmaria deusta belongs to the ustulinoid taxa and can be distinguished from other ustulinoid Kretzschmaria species by smaller ascospores, except for K. zonata (Rogers \& Ju 1998). Rogers \& Ju (1998) believed that $K$. deusta is a fungus of the Northern temperate regions. Up to now, there are indeed no reliable reports of this species from tropical (1998), except for slight differences in ascospore size $(25-34 \times 5.5-8(-9)$ vs. $27-35 \times 7-9 \mu \mathrm{m})$.

\section{Discussion}

From the results of this study, we introduce two new species of Kretzschmaria, based on morphological and molecular phylogenetic data. In addition to morphological differences, $K$. hedjaroudei is phylogenetically distinct from its closest relatives, $K$. deusta. The second new species, $K$. iranica, differs from $K$. pavimentosa in morphology and is also phylogenetically distinct. According to morphological data, $K$. zonata is similar to $K$. deusta but in the combined phylogenetic tree it is closely related to $K$. pavimentosa and $K$. iranica. Unfortunately, no sequence of the type or any other specimen of $K$. zonata was available for comparison to the Iranian specimens. Hsieh et al. (2010) conducted the first phylogenetic study of this genus based on a combined matrix of $\beta$-tubulin, $\alpha$-actin and RPB2 genes and emphasized that molecular data did not correspond to morphological data. That way, the two subgroups of Kretzschmaria (kretzschmarioid and ustulinoid) did not group together. A recent phylogenetic study by Yun et al. (2016) using partial DNA sequences of multiple genes ( $\beta$-tubulin, ITS and RPB2) revealed similar results to those of Hsieh et al. (2010), which is also the case in our phylogenetic analyses. These results show that this genus needs additional comprehensive studies with polyphasic approaches before a stable taxonomy of the group can be achieved.

\section{Acknowledgements}

The Ministry of Science, Research and Technology (MSRT) of Iran is gratefully acknowledged for the financial support.

\section{References}

Carbone I, Kohn LM. 1999 - A method for designing primer sets for speciation studies in filamentous ascomycetes. Mycologia 91, 553-556.

Daranagama DA, Hyde KD, Sir EB, Thambugala KM et al. 2018 - Towards a natural classification and backbone tree for Graphostromataceae, Hypoxylaceae, Lopadostomataceae and Xylariaceae. Fungal Diversity 88, 1-165.

Helaly SE, Thongbai B, Stadler M. 2018 - Diversity of biologically active secondary metabolites from endophytic and saprotrophic fungi of the ascomycete order Xylariales. Natural Products Reports 35, 992-1014.

Hirata T, Takamatsu S. 1996 - Nucleotide sequence diversity of rDNA internal transcribed spacers extracted from conidia and cleistothecia of several powdery mildew fungi. Mycoscience $37,265-270$.

Hladki AI, Romero AI. 2001 - The genus Kretzschmaria from Tucumán, Argentina. Mycotaxon $79,481-496$.

Hsieh HM, Ju YM, Rogers JD. 2005 - Molecular phylogeny of Hypoxylon and closely related genera. Mycologia 97,914-923.

Hsieh HM, Lin CR, Fang MJ, Rogers JD et al. 2010 - Phylogenetic status of Xylaria subgenus Pseudoxylaria among taxa of the subfamily Xylarioideae (Xylariaceae) and phylogeny of the taxa involved in the subfamily. Molecular Phylogenetics and Evolution 54,957-969. 
Katoh K, Misawa K, Kuma K, Miyata T. 2002 - MAFFT: a novel method for rapid multiple sequence alignment based on fast fourier transform. Nucleic Acids Research 30, 3059-3066.

Khodaparast SA, Takamatsu S, Harada M, Abbasi M, Samadi S. 2012 - Additional rDNA ITS sequences and its phylogenetic consequences for the genus Leveillula with emphasis on conidium morphology. Mycological Progress 11,741-752.

Kumar S, Stecher G, Tamura K. 2016 - MEGA7: Molecular evolutionary genetics analysis version 7.0 for bigger datasets. Molecular Biology and Evolution 30, 2725-2729.

Martin P. 1970 - Studies in the Xylariaceae: VIII. Xylaria and its allies. Journal of South African Botany 36, 71-83.

Mugambi GK, Huhndorf SM, Rogers JD. 2009 - Two new xylariaceous species from Kenya. Mycotaxon 108,499-504.

Pereira J, Rogers JD, Bezerra JL. 2009 - New Xylariaceae taxa from Brazil. Sydowia 61(2), 321325.

Rogers JD, Ju YM. 1998 - The genus Kretzschmaria. Mycotaxon 68, 345-393.

Rogers JD, Ju YM. 2004 - Kretzschmaria varians sp. nov., Xylaria coremiifera sp. nov. And Xylaria umbonata sp. nov. from Costa Rica. Mycological Progress 3, 37-40.

Saber M. 2002 - Three new records of Ascomycetes from Iran. Proceeding of the $15^{\text {th }}$ Iranian Plant Protection Congress, vol. II, 172.

Senanayake IC, Maharachchikumbura SSN, Hyde KD, Bhat JD et al. 2015 - Towards unraveling relationships in Xylariomycetidae (Sordariomycetes). Fungal Diversity 73, 73-144.

Silvestro D, Michalak I. 2012 - raxmlGUI: a graphical front-end for RAxML. Organisms Diversity \& Evolution 12, 335-337.

Sir EB, Lambert C, Wendt L, Hladki AI et al. 2016 - A new species of Daldinia (Xylariaceae) from the Argentine subtropical montane forest. Mycosphere 7, 1378-1388.

Stamatakis E. 2006 - RAxML-VI-HPC: maximum likelihood-based phylogenetic analyses with thousands of taxa and mixed models. Bioinformatics 22, 2688-2690.

U'Ren JM, Miadlikowska J, Zimmerman NB, Lutzoni F et al. - 2016 Contributions of North American endophytes to the phylogeny, ecology, and taxonomy of Xylariaceae (Sordariomycetes, Ascomycota). Molecular Phylogenetics and Evolution 98, 210-232.

Walsh PS, Metzger DA, Higuchi R. 1991 - Chelex 100 as a medium for simple extraction of DNA for PCR-based typing from forensic material. Biotechniques 10, 506-513.

Wendt L, Sir EB, Kuhnert E, Heitkämper S et al. 2018 - Resurrection and emendation of the Hypoxylaceae, recognised from a multi-gene genealogy of the Xylariales. Mycological Progress 17, 115-154.

White TJ, Bruns T, Lee S, Taylor J. 1990 - Amplification and direct sequencing of fungal ribosomal RNA genes for phylogenetics. In: PCR Protocols: a guide to methods and applications. (Innis MA, Gelfand DH, Sninsky JJ, White TJ, eds). Academic Press, New York, USA, 315-322.

Wijayawardene NN, Hyde KD, Lumbsch HT, Liu JK et al. 2018 - Outline of Ascomycota: 2017. Fungal Diversity 88: 167-263.

Yun JH, Jo JW, Lee JH, Han SK et al. 2016 - Kretzschmaria quercicola sp. nov., an undescribed fungus from living oak in Mt. Daeryong, Korea. Mycobiology 44(2), 112-116. 